ARTICLE

\title{
Direct copolymerization of ethylene with protic comonomers enabled by multinuclear $\mathrm{Ni}$ catalysts
}

\author{
Gang Ji ${ }^{1}$, Zhou Chen ${ }^{1}$, Xiao-Yan Wang ${ }^{1}$, Xiao-Shan Ning ${ }^{1}$, Chong-Jie Xu ${ }^{1}{ }^{2}$, Xing-Min Zhang ${ }^{2}$, Wen-Jie Tao',

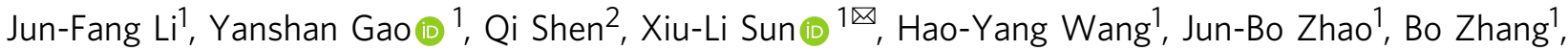 \\ Yin-Long Guo ${ }^{1 凶}$, Yanan Zhao ${ }^{3}$, Jiajie Sun ${ }^{3}$, Yi Luo $^{3,4 凶} \&$ Yong Tang (iD) ${ }^{1 凶}$
}

Ethylene/polar monomer coordination copolymerization offers an attractive way of making functionalized polyolefins. However, ethylene copolymerization with industrially relevant short chain length alkenoic acid remain a big challenge. Here we report the efficient direct copolymerization of ethylene with vinyl acetic acid by tetranuclear nickel complexes. The protic monomer can be extended to acrylic acid, allylacetic acid, $\omega$-alkenoic acid, allyl alcohol, and homoallyl alcohol. Based on X-ray analysis of precatalysts, control experiments, solventassisted electrospray ionization-mass spectrometry detection of key catalytic intermediates, and density functional theory studies, we propose a possible mechanistic scenario that involves a distinctive vinyl acetic acid enchainment enabled by $\mathrm{Ni} \cdots \mathrm{Ni}$ synergistic effects. Inspired by the mechanistic insights, binuclear nickel catalysts are designed and proved much more efficient for the copolymerization of ethylene with vinyl acetic acid or acrylic acid, achieving the highest turnover frequencies so far for both ethylene and polar monomers simultaneously.

\footnotetext{
${ }^{1}$ State Key Laboratory of Organometallic Chemistry, Shanghai Institute of Organic Chemistry, Chinese Academy of Sciences, Shanghai, China. ${ }^{2}$ School of Chemistry and Chemical Engineering, Soochow University, Suzhou, China. ${ }^{3}$ State Key Laboratory of Fine Chemicals, School of Chemical Engineering, Dalian

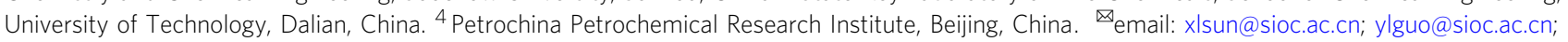
luoyi@dlut.edu.cn; tangy@sioc.ac.cn
} 
olyethylene (PE) is one of the most used plastic materials, which is in part due to its chemical stability/inertness. However, the non-polar feature also limits its further applications that require adhesiveness, compatibility, toughness, adhesion, surface properties (dyeability, printability, etc.) and rheological properties ${ }^{1}$. Industrial applications mainly rely on post-polymerization functionalization of polyolefins, which are usually under harsh conditions and lack selectivity due to the radical process that induces chain scission and cross-linking etc ${ }^{2}$. Ethylene coordination copolymerization with polar monomer is a straightforward option attracting much attention, but only limited success has been achieved so far. For example, group 4 transition metal catalysts have been very successful in olefin polymerizations, however, their use in polar monomer copolymerization is severely limited due to high catalyst oxophilicity ${ }^{3-5}$. Late transition metal catalysts ${ }^{6-13}$ such as Brookhart-9,13-16, Grubbs- ${ }^{12,17}$, Drent- ${ }^{11,18-20}$, and Mitsubishi-type ${ }^{21-23}$ complexes, etc. exhibit greater polar comonomer tolerance and used in ethylene copolymerizations with a wide range of polar comonomers. But there is still a lack of catalyst systems with high efficiency and $M_{\mathrm{w}}$ capability in olefin-polar monomer copolymerization. Thus, developing new catalyst systems is still a great challenge that attracts considerable attention from both academia and industry ${ }^{24}$.

Even more challenging is to incorporate short chain length alkenoic acid, such as acrylic acid (AA) and vinyl acetic acid (VA) into PEs ${ }^{25-27}$, since: $(i)$ acidic proton in comonomers such as alkenoic acids can protonate and thus poison the catalyst ${ }^{27}$; (ii) strong carboxylate coordination can promote the formation of stable chelate complex or $\beta$-X elimination ${ }^{28,29}$. Thus, although a few results of direct copolymerization of ethylene with AA using palladium catalyst based on either phosphinesulfonate or diphosphazane monoxide ligand were reported ${ }^{25-27}$, AA are more harmful to enchainment than the corresponding aprotic monomers in all the cases. For example, less than half AA enchainment was obtained comparing to methyl acrylate (MA) in ethylene copolymerization using phosphinesulfonate palladium under identical conditions ${ }^{26}$. As PEs containing - $\mathrm{COOH}$ groups are particularly important targets ${ }^{30}$, we are interested in the topic for several years ${ }^{4,31,32}$. Here we show a tetranuclear Ni catalyst system, which shows much higher efficiency in enchaining protic VA without compromising activity or $M_{\mathrm{w}}$ capability vs. its aprotic analog methyl vinyl acetate (MVA). The same trends are also seen for a range of protic monomers such as allylacetic acid, $\omega$ alkenoic acid, allyl alcohol and homoallyl alcohol, exhibiting abnormal effects in contrast to previous catalyst systems. X-Ray analysis of precatalysts, control experiments, solvent-assisted electrospray ionization-mass spectrometry (SAESI-MS) detection of key intermediates, and DFT studies reveal a possible mechanistic scenario that involves a distinctive VA enchainment enabled by $\mathrm{Ni} \cdots \mathrm{Ni}$ synergistic effects. Based on the mechanistic insights, a binuclear nickel catalyst is further designed and proves much more efficient for the copolymerization of ethylene with either VA or AA, achieving the highest TOFs so far for both ethylene and polar monomers simultaneously ${ }^{25-27}$.

\section{Results and Discussion}

Synthesis and characterization of tetranuclear nickel complexes. Complexes 1a-c were synthesized in good yields. Bubbling $\mathrm{O}_{2}{ }^{33}$ into acetonitrile or toluene solution of $\mathbf{1 a}-\mathbf{c}$ at $40^{\circ} \mathrm{C}$ leads to solution color changes from blue to red or brown (Supplementary Methods 1.2). After recrystallization from $\mathrm{CH}_{3} \mathrm{CN} / n$-hexane or $\mathrm{THF} / n$-hexane solution, pure $\mathbf{2 a}$-c were obtained and characterized by Elem. Anal. and further confirmed by X-ray analysis (Fig. 1a, b). As shown in Fig. 1b, both $2 \mathrm{a}$ and $2 \mathrm{c}$ are tetranuclear nickel clusters composed of two oxidized ligands. The Ni1..Ni2 distances for $2 \mathrm{a}$ and $2 \mathrm{c}$ are $3.331 \AA$ and $3.324 \AA$, respectively, which are shorter than the sum of van der Waals radii of two nickel atoms $(4.44 \AA)^{34}$. These are among one of the shortest $\mathrm{Ni} \cdots \mathrm{Ni}$ distances in bimetallic $\mathrm{Ni}$ complexes for olefin polymerization such as by Marks $(\sim 3.1 \AA)^{35}$, Takeuchi $(4.73 \AA)^{36}$, which show great $\mathrm{Ni} \cdot \cdots \mathrm{Ni}$ synergistic effects. The Nil-O1 bond lengths are 1.991(5) and 2.002(3) $\AA$, and the Ni2-O1 bond lengths are 2.041(5) and 2.056(3) Å for 2a and 2c, respectively, which are slightly longer than that in salicylaldiminato $\mathrm{Ni}(\mathrm{II})$ complex $(1.910 \AA)^{10}$, suggesting similar $\mathrm{Ni}-\mathrm{O}$ bond strengths/robustness even for the shared $\mathrm{O}$ in 2.

Ethylene polymerization. Upon activation with modified methylaluminoxane (MMAO) ${ }^{37}$, the conversion of mononuclear 1a-c into tetranuclear $\mathbf{2 a - c}$ change them from inactive catalysts into very active ones (Table 1, entries 1-3 vs. 4-6). For example, 2a promotes ethylene polymerization with activity as high as $2928 \mathrm{~kg} /(\mathrm{mol} \mathrm{Cat}) \cdot \mathrm{h} \cdot \mathrm{atm}$, and high $M_{\mathrm{w}}, 850 \mathrm{~kg} / \mathrm{mol}$ (entry 4). Replacing ${ }^{i} \mathrm{Pr}$ group on aniline by methyl group (2b) or $\mathrm{Cl}(2 \mathrm{c})$ results in slightly decreased activity and PE $M_{\mathrm{w}}$ (entries 5-6).

Ethylene + polar monomer copolymerization. Precatalysts 2a-c are used for ethylene + polar monomer copolymerizations following three different procedures (Table 2, Supplementary Methods 1.3). Procedure A: polar monomer is mixed with MMAO in toluene under ethylene for $5 \mathrm{~min}$ before 2 is introduced to start polymerization; Procedure B: polar monomer is pretreated with MMAO for $24 \mathrm{~h}$ before 2 is introduced under ethylene to start polymerization without additional MMAO; Procedure C: polar monomer is pretreated with 1.2 equiv. $\mathrm{R}_{3} \mathrm{Al}$ $\left(\mathrm{R}=\mathrm{Me}\right.$, TMA; $\mathrm{R}=\mathrm{Et}, \mathrm{TEA} ; \mathrm{R}={ }^{i} \mathrm{Bu}$, TIBA) for $24 \mathrm{~h}$ before MMAO and $\mathbf{2}$ are introduced under ethylene to start polymerization.

Following Procedure A, i.e., no polar monomer pretreatment, precatalyst $\mathbf{2 a}$ catalyzes ethylene + vinylacetic acid (VA) copolymerization with an activity of $54 \mathrm{~kg} /(\mathrm{mol} \mathrm{Cat}) \cdot \mathrm{h} \cdot \mathrm{atm}$ and great VA incorporation (2.1 mol\%, entry 1$)$. VA incorporation is confirmed by a combined NMR $\left({ }^{1} \mathrm{H},{ }^{13} \mathrm{C}\right.$, COSY, HSQC, HMBC) and ATR-IR characterizations (Supplementary Note 1 and Supplementary Fig. 17). Unexpectedly, following Procedure B, i.e., mixing VA with $\mathrm{MMAO}$ for $24 \mathrm{~h}$, results in a marginal increase of activity to $84 \mathrm{~kg} /(\mathrm{mol} \mathrm{Cat}) \cdot \mathrm{h} \cdot \mathrm{atm}$ with a significant $5.3 \times$ decrease in VA incorporation to $0.4 \mathrm{~mol} \%$ (entry 5 vs. 1). This trend is counterintuitive as pretreating polar monomers with aluminoxane or $\mathrm{R}_{3} \mathrm{Al}$ is an effective strategy for group $4^{3,4,32}$ and late $\mathrm{s}^{38,39}$ transition metal complexes catalyzed polar monomer copolymerizations. It is further confirmed by control experiments following Procedure $\mathrm{C}$, in which the copolymerizations with $\mathbf{2 a}$ only enchain $\sim 0.5 \mathrm{~mol} \% \mathrm{VA}$ regardless of the type of $\mathrm{R}_{3} \mathrm{Al}$ used (entries 6-8). We also tried corresponding aprotic methyl vinylacetate (MVA) following Procedure A, in which comparable activity is obtained but with obviously reduced comonomer incorporation $(1.1 \mathrm{~mol} \%$ vs. $2.1 \mathrm{~mol} \%)$ and $M_{\mathrm{w}}(15 \mathrm{~kg} / \mathrm{mol}$ vs. $33 \mathrm{~kg} / \mathrm{mol}$ ) (entry 9 vs. 1). These intriguing trends likely suggest the abnormal effects of $-\mathrm{COOH}$, in contrast to previous catalyst systems ${ }^{11,40}$, showing the unique character of $\mathbf{2}$ in maintaining good activity and enhancing protic monomer enchainment when Procedure $\mathrm{A}$ is followed. In contrast, the well-established $\alpha$ diimine $\mathrm{NiBr}_{2} 3$ (Fig. 1c) only gives good activity in ethylene + VA copolymerization by pretreating VA with TMA (Procedure C) but shows negligible activity following Procedure A (entry 21 vs. 22). While neutral o-bis(aryl)-phosphinophenolate nickel catalysts $4^{23}$ and $5^{21}$ (Fig. 1c) are known for good tolerance toward polar monomers ${ }^{21,22}$, these catalysts show negligible activity following Procedure A or typical literature conditions 
a

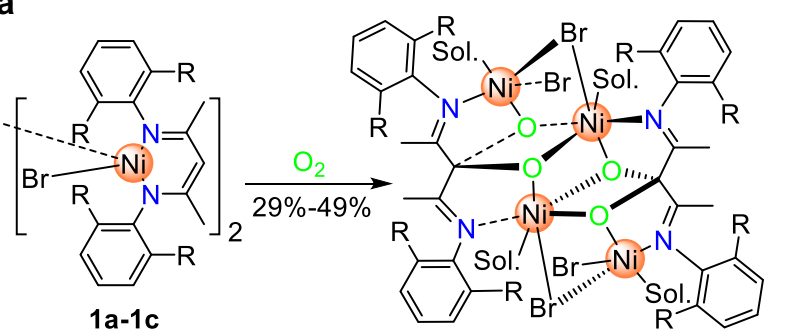

2a $\mathrm{R}={ }^{i} \mathrm{Pr}$, Sol. $=\mathrm{CH}_{3} \mathrm{CN}$

2b $\mathrm{R}=\mathrm{Me}$, Sol. $=\mathrm{THF}$

2c $\mathrm{R}=\mathrm{Cl}$, Sol. $=\mathrm{THF}$ (c)

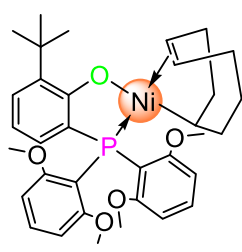

4

3

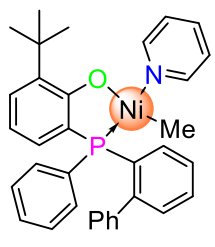

5

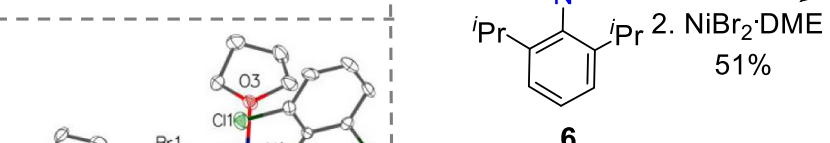

6

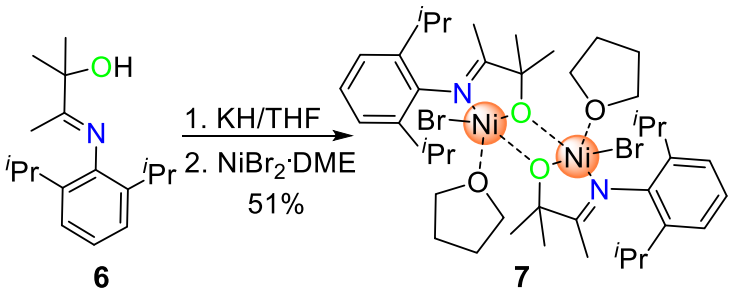

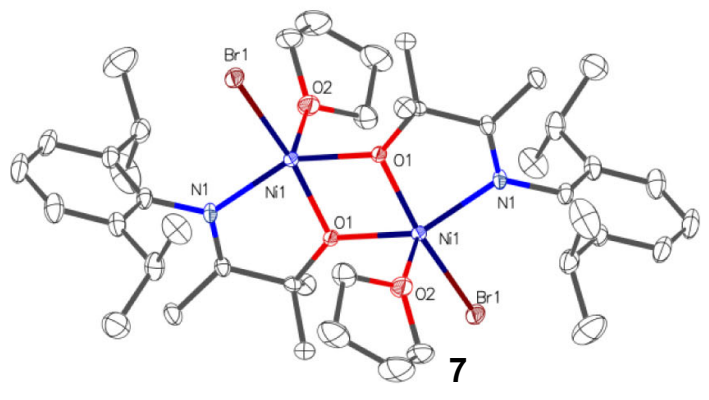

Fig. 1 Structure formula and single crystal structures of catalysts. a Synthesis of tetranuclear nickel complexes $\mathbf{2 a - 2 c}$. $\mathbf{b}$ Single crystal structures of complexes $\mathbf{2 a}$ and $\mathbf{2 c}$. c Literature reported nickel complexes 3, $\mathbf{4}$ and $\mathbf{5}$. d Synthesis of complex 7. e Single crystal structure of complex $\mathbf{7}$.

Table 1 Ethylene polymerizations catalyzed by Ni catalysts 1, 2 and 7.

\begin{tabular}{|c|c|c|c|c|c|c|c|c|c|}
\hline Entrya & Cat. ( $\mu \mathrm{mol})$ & Yield (g) & Act. ${ }^{b}$ & TOFc & $M_{\mathrm{w}}{ }^{\mathrm{d}}(\mathrm{kg} / \mathrm{mol})$ & $\emptyset^{d}$ & $\mathbf{B}^{\mathbf{e}}$ & Chains/Cat. & $T_{m}^{f}\left({ }^{\circ} \mathrm{C}\right)$ \\
\hline 1 & $\mathbf{1 a}(2.5)$ & trace & - & - & - & - & - & - & - \\
\hline 2 & 1b (2.5) & trace & - & - & - & - & - & - & - \\
\hline 3 & 1c $(2.5)$ & trace & - & - & - & - & - & - & - \\
\hline 4 & $\mathbf{2 a}(1.25)$ & 0.61 & 2928 & 104571 & 850 & 2.4 & 22 & 1.4 & 108 \\
\hline 5 & $\mathbf{2 b}(1.25)$ & 0.25 & 1200 & 42857 & 439 & 4.6 & 22 & 2.1 & 109 \\
\hline 6 & 2c (1.25) & 0.18 & 864 & 30857 & 566 & 2.4 & 19 & 0.6 & 110 \\
\hline 7 & $\mathbf{2 a}(0.25)$ & 0.24 & 5760 & 205714 & 904 & 2.1 & 18 & 2.2 & 109 \\
\hline $8^{g}$ & $7(2.5)$ & none & - & - & - & - & - & - & - \\
\hline
\end{tabular}

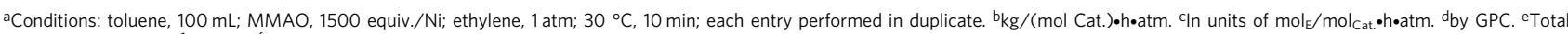
branches/1000 C, by ${ }^{1} \mathrm{H}$ NMR. ${ }^{\mathrm{f}} \mathrm{By}$ DSC. gNeither PE nor oligomers (by GC) detected in the presence of $\mathrm{MMAO}, \mathrm{MAO}$, or $\mathrm{Et}_{2} \mathrm{AICl}$.

(entries 23-26 and Supplementary Table 3). Thus, these results further demonstrate the difference of cluster catalyst 2 from the known Ni catalysts.

Concurred with the trend observed in $\mathbf{2 a}$ catalyzed ethylene copolymerization with protic monomer VA, i.e., enhanced comonomer incorporation, there is also a similar trend for both 4-pentenoic acid (PA) and 9-undecenoic acid (UA) following Procedure A vs. Procedure C, 5.8 vs. $1.0 \mathrm{~mol} \%$ for PA (entry 10 vs. 11) and 13.9 vs. 2.7 mol\% (entry 12 vs. 13) for UA. In addition, alkenol monomers can also be efficiently incorporated in $\mathbf{2 a}$ catalyzed ethylene copolymerizations. For example, higher HAA incorporation is achieved following Procedure A vs. Procedure $\mathrm{C}$ ( 2.7 vs. $1.3 \mathrm{~mol} \%$, entry 15 vs. 17 ); and the incorporation of allylic alcohol (A-ol) is much higher than its aprotic analog AME ( $1.8 \mathrm{~mol} \%$ vs. $0.04 \mathrm{~mol} \%$, entry 18 vs. 19$)$. Thus, the above abnormal effects that protic monomer is incorporated much more efficiently than the corresponding aprotic monomers are extensively observed in 2a-catalyzed ethylene copolymerization with protic polar monomers.

Rationale for the abnormal effects. To get insights into the effects, we first designed ligand $\mathbf{6}$ and tried to synthesize mononuclear nickel complex with similar coordination environment to complex 2 to investigate whether it is a ligand effect or a $\mathrm{Ni} \cdots \mathrm{Ni}$ synergistic effect. The complex 7 shows very similar $\mathrm{Ni}-\mathrm{O}$ and $\mathrm{Ni}-$ $\mathrm{N}$ bond parameters to $\mathbf{2 a}$ and $\mathbf{2 c}$ (Fig. 1d, e). However, 7 is inert in ethylene polymerization (Table 1 , entry 8 ). This result suggests less ligand effect and that there may be a substantial synergism between the neighboring nickels during the copolymerization process.

To further understand the $\mathrm{Ni} \cdots \mathrm{Ni}$ synergistic effects ${ }^{41}$, a recently developed solvent-assisted electrospray ionization-mass spectrometry (SAESI-MS) technique was used for straightforward capture of the species ${ }^{42}$. With SAESI-MS, we observed a strong 
Table 2 Copolymerization of ethylene and various polar monomers.

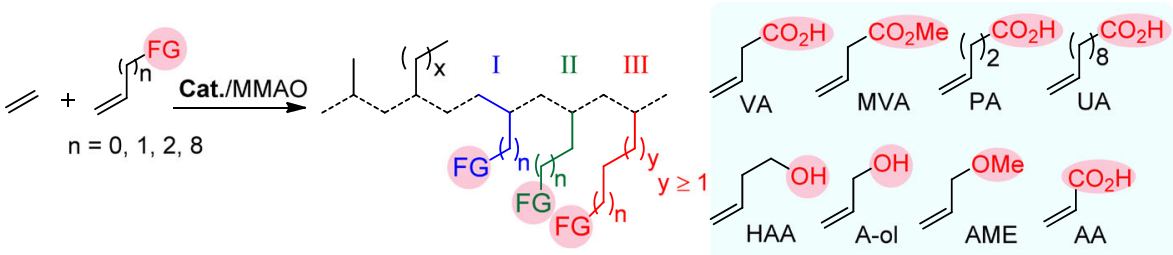

Procedures used in ethylene + polar monomer copolymerization

Procedure A: no pretreatment

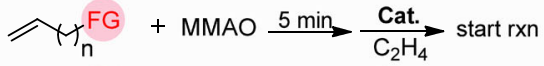

Procedure B: MMAO $24 \mathrm{~h}$ pretreatment

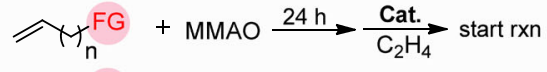

Procedure $\mathrm{C}: \mathrm{R}_{3} \mathrm{Al} 24 \mathrm{~h}$ pretreatment

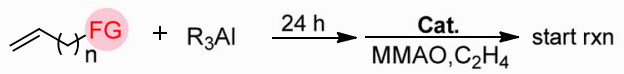

\begin{tabular}{|c|c|c|c|c|c|c|c|c|c|c|c|c|}
\hline$\overline{\text { Ent. }^{a}}$ & Cat. $(\mu \mathrm{mol})$ & Comon. (M) & $\begin{array}{l}\text { Pretreatment } \\
\text { procedure\& } \\
\text { reagent }\end{array}$ & Yield (g) & Act. $b$ & $\begin{array}{l}\text { TOFC (E/ } \\
\text { comon.) }\end{array}$ & $M_{w}^{d}$ & $\oplus^{d}$ & Incorp.e (mol\%) & $B^{f}$ & Chains /Cat. & $T_{c} \mathrm{~g}\left({ }^{\circ} \mathrm{C}\right)$ \\
\hline 1 & $\mathbf{2 a}(10.0)$ & VA (0.3) & $A_{,-}$ & 0.09 & 54 & $1807 / 40$ & 33 & 3.3 & 2.1 & 76 & 1.0 & 79 \\
\hline 3 & $\mathbf{2 b}(10.0)$ & VA (0.3) & $A_{,}-$ & 0.03 & 18 & $610 / 11$ & 25 & 2.7 & 1.7 & 68 & 0.4 & 76 \\
\hline 4 & 2c (10.0) & VA (0.3) & $A_{,}-$ & 0.02 & 12 & $398 / 10$ & 26 & 2.9 & 2.4 & 74 & 0.3 & 74 \\
\hline 5 & $\mathbf{2 a}(10.0)$ & VA (0.3) & $\mathrm{B}, \mathrm{MMAO}$ & 0.14 & 84 & 2965/11 & 102 & 3.6 & 0.4 & 76 & 0.5 & 99 \\
\hline 8 & $\mathbf{2 a}(10.0)$ & VA (0.3) & C, TIBA & 0.19 & 114 & $4018 / 17$ & 33 & 3.6 & 0.4 & 55 & 2.1 & 92 \\
\hline 9 & $\mathbf{2 a}(10.0)$ & $\operatorname{MVA}(0.3)$ & $A,-$ & 0.11 & 66 & $2267 / 25$ & 15 & 3.0 & 1.1 & 79 & 2.1 & 81 \\
\hline $10^{\mathrm{i}}$ & $\mathbf{2 a}(5.0)$ & PA $(0.15)$ & $A,-$ & 0.17 & 408 & $\begin{array}{l}11949 / \\
733\end{array}$ & 31 & 3.8 & 5.8 & 75 & 4.3 & 39 \\
\hline $11^{i}$ & $\mathbf{2 a}(5.0)$ & PA (0.15) & C, TMA & 0.28 & 672 & $\begin{array}{l}23168 / \\
233\end{array}$ & 122 & 2.6 & 1.0 & 38 & 1.2 & 82 \\
\hline $12^{i}$ & $\mathbf{2 a}(1.25)$ & UA $(0.2)$ & A. - & 0.14 & 1344 & $\begin{array}{l}23235 / \\
3763\end{array}$ & n.d. & n.d. & 13.9 & 24 & - & 30 \\
\hline $15^{j}$ & $\mathbf{2 a}(5.0)$ & $\operatorname{HAA}(0.2)$ & $A_{,}^{-}$ & 0.21 & 252 & $\begin{array}{l}8399 / \\
233\end{array}$ & 87 & 2.9 & 2.7 & 49 & 1.4 & 70 \\
\hline $16^{\mathrm{j}}$ & $\mathbf{2 a}(15.0)$ & $\operatorname{HAA}(0.2)$ & $A_{1}-$ & 0.37 & 148 & $\begin{array}{l}4623 / \\
257\end{array}$ & 39 & 3.2 & 5.3 & 60 & 2.0 & 55 \\
\hline $17^{j}$ & $\mathbf{2 a}(5.0)$ & $\operatorname{HAA}(0.2)$ & C, TMA & 0.80 & 960 & $\begin{array}{l}33174 / \\
432\end{array}$ & 261 & 4.0 & 1.3 & 32 & 2.5 & 86 \\
\hline $18^{k}$ & $\mathbf{2 a}(25.0)$ & A-ol (0.4) & $A_{1}-$ & 0.10 & 24 & $826 / 15$ & 8 & 3.2 & 1.8 & 86 & 1.6 & 59 \\
\hline $19^{k}$ & $\mathbf{2 a}(25.0)$ & $\operatorname{AME}(0.4)$ & $A_{1}-$ & 0.10 & 24 & $856 / 0.3$ & 14 & 3.2 & 0.04 & 69 & 0.9 & 91 \\
\hline $20^{k}$ & $\mathbf{2 a}(25.0)$ & $\mathrm{AA}(0.4)$ & $A^{\prime}-$ & 0.12 & 29 & $1020 / 3$ & 21 & 5.1 & 0.3 & 81 & 1.2 & 70 \\
\hline 21 & $3(40.0)$ & VA $(0.3)$ & $A_{,}-$ & trace & - & - & - & - & - & - & - & - \\
\hline 22 & $3(40.0)$ & VA (0.3) & C, TMA & 0.81 & 122 & $4313 / 9$ & 62 & 2.0 & 0.2 & 118 & 0.7 & n.d. \\
\hline
\end{tabular}

peak that corresponds to $[\mathbf{2 a}+\mathrm{Br}]^{-}$in dichloromethane (DCM), suggesting the cluster nickel complex $\mathbf{2 a}$ does not collapse in DCM (Fig. 2b). In contrast, only a signal at $\mathrm{m} / \mathrm{z} 478$ was observed in 7/DCM, suggesting the dimer collapses into monomer (Fig. 2a). Furthermore, a major signal at $\mathrm{m} / \mathrm{z} 1291$ was captured when $2 \mathrm{a}$ was in situ mixed with $\mathrm{MMAO}(\mathrm{Al} / \mathrm{Ni}=25$, mimicking the polymerization conditions in Supplementary Table 1, entry 5), which is likely attributed to species $[2 \mathbf{a}-2 \mathrm{Br}+\mathrm{H}]^{+}(\mathbf{2 a a})$ by reasonable inference (Fig. 2c). 2aa is likely formed via facile MMAO alkylation and then $\beta-\mathrm{H}$ elimination during 2a 
a
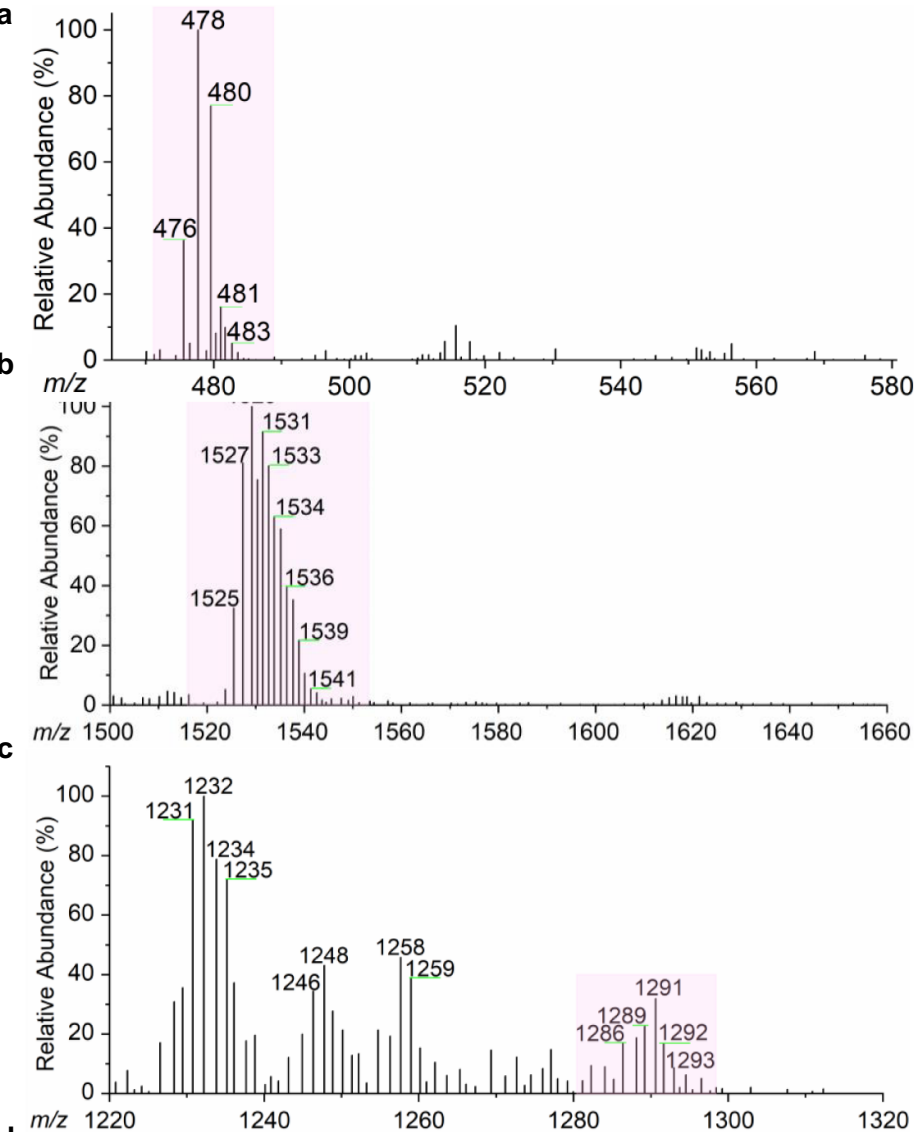

d

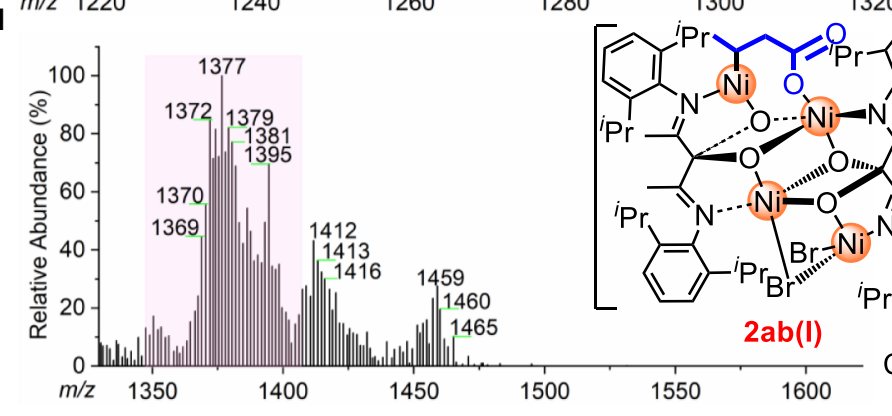

e VA mixed with 2 equiv. of MMAO

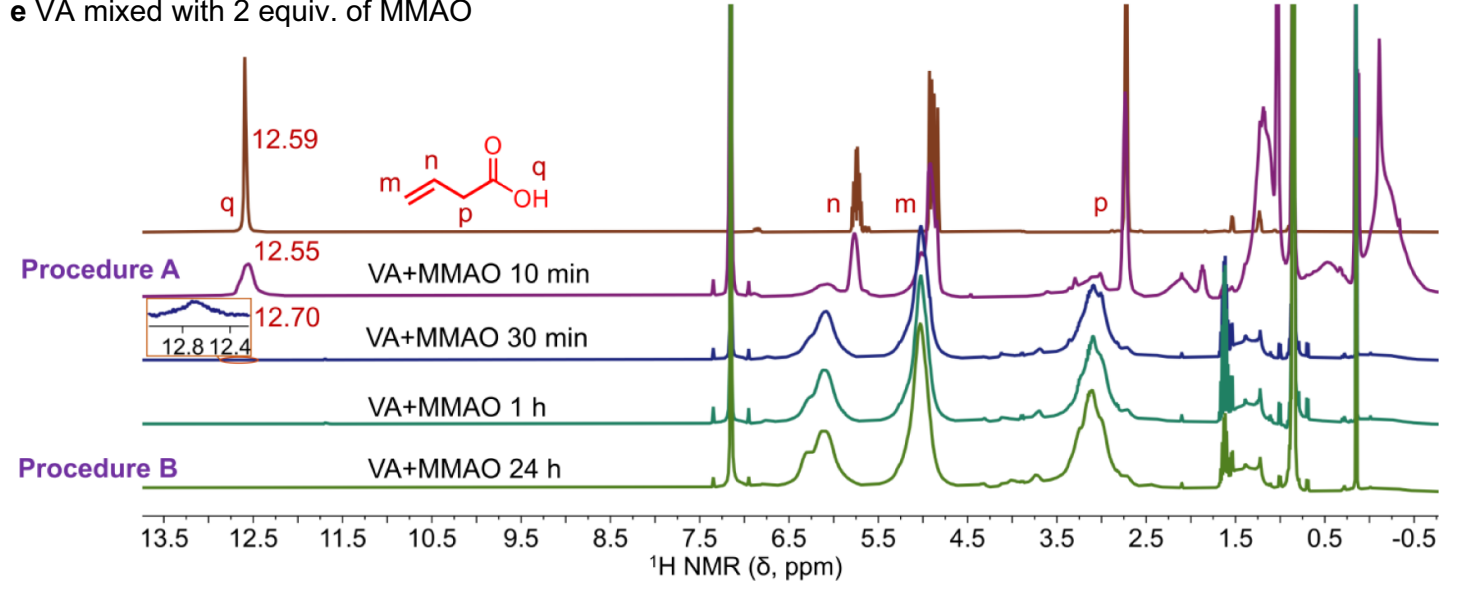

Fig. 2 SAESI-MS and NMR spectra. a SAESI-MS spectra of $\mathbf{7}$ in DCM showing signals at m/z 478 [(0.5) $\mathbf{7}+\mathrm{Br}]$ - b SAESI-MS spectra of $\mathbf{2 a}$ showing

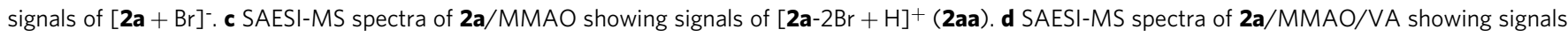
of $[\mathbf{2} \mathbf{a}-2 \mathrm{Br}+\mathrm{H}+\mathrm{VA}]^{+}(\mathbf{2} \mathbf{a b})$. e ${ }^{1} \mathrm{H}$ NMR tracking reaction mimicking polar monomer pretreatment procedures (in $\mathrm{C}_{6} \mathrm{D}_{6}, 25{ }^{\circ} \mathrm{C}$ ). 
a Computed energy profiles for Ni mediated copolymerization of ethylene with VA anion.

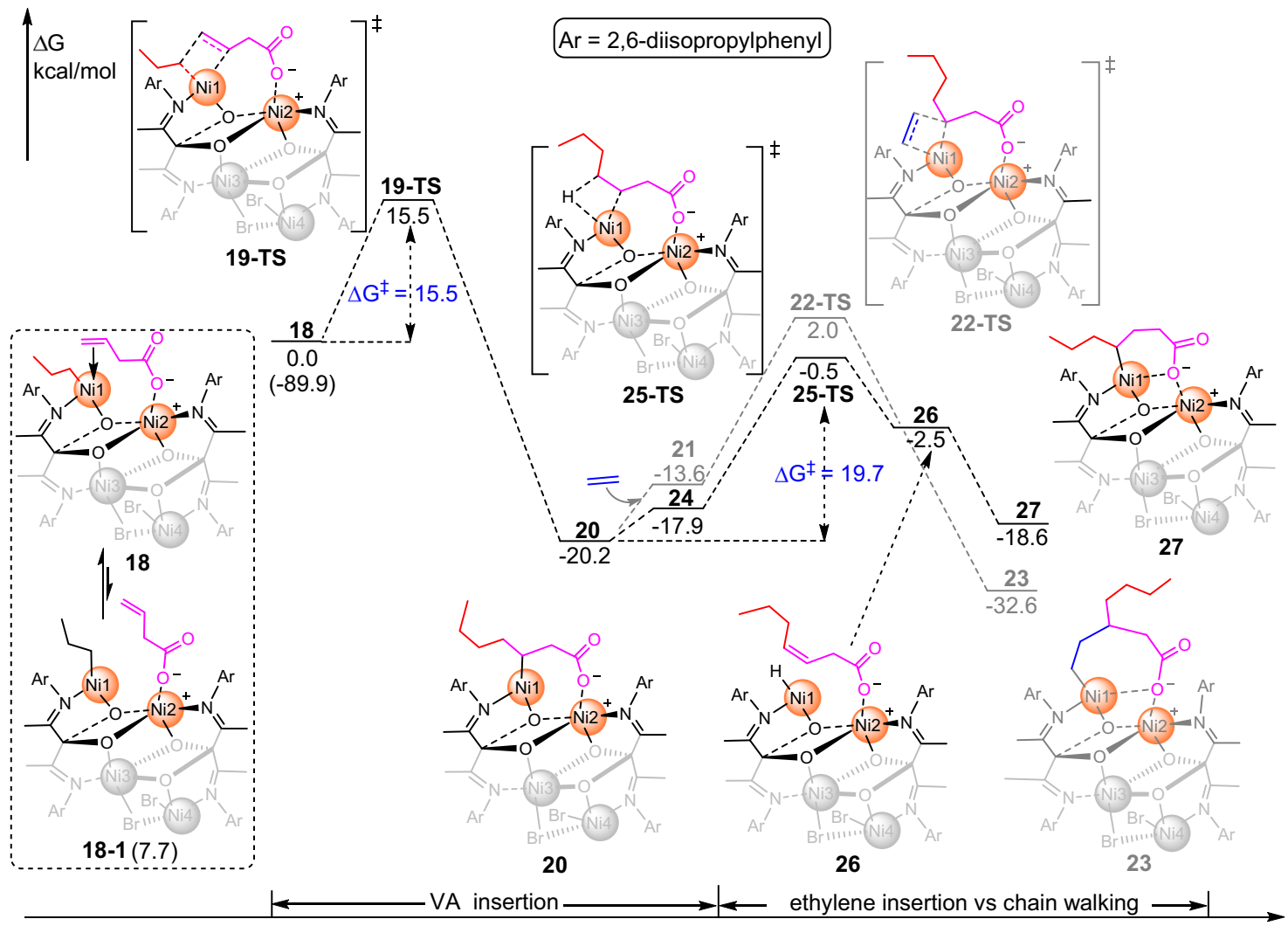

b Calculated reaction energy of the proton transfer.
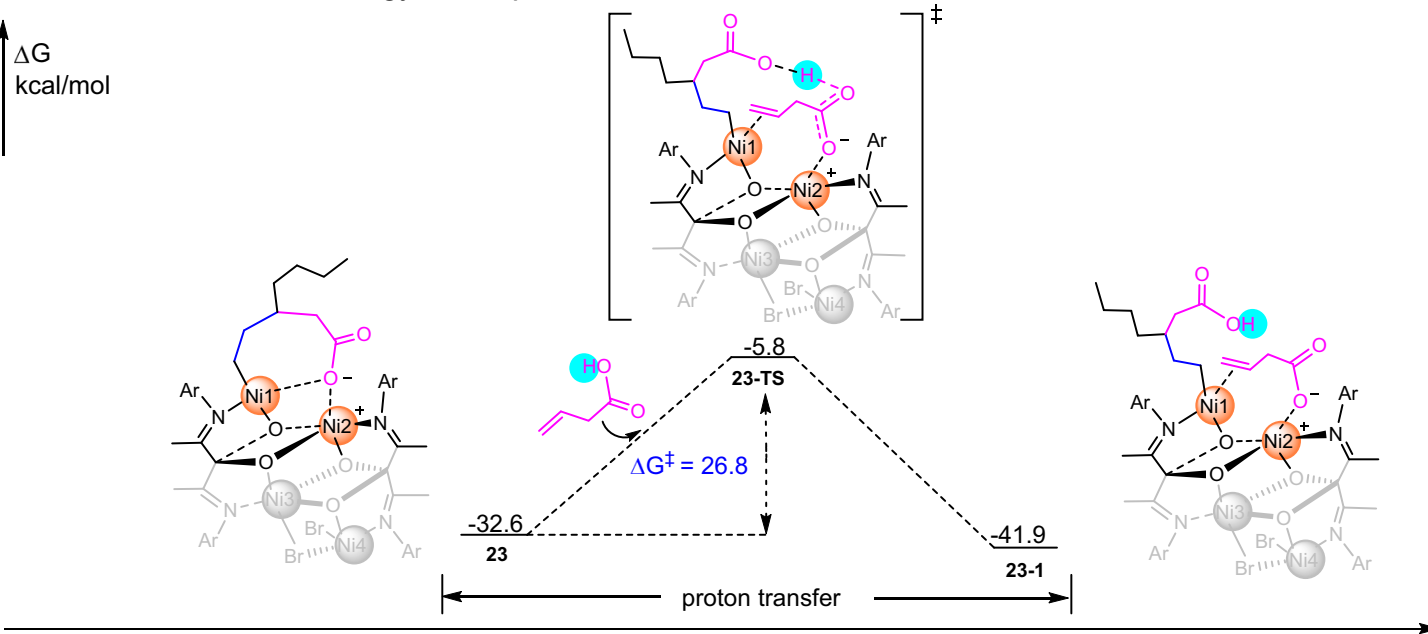

Fig. 3 DFT calculations. a Computed energy profiles (M06(SMD)/6-311 $+G^{\star \star} \cap S D D / / B 3 L Y P / 6-31 G^{\star} \cap L A N L 2 D Z$, the solvent used in calculations is toluene) for $\mathrm{Ni}$ mediated copolymerization of ethylene with $\mathrm{VA}$ anion (the effect of large aluminum counterion was not considered). The energies are relative to the intermediate 18. b Calculated reaction energy (M06(SMD)/6-311 + G*^ $\cap S D D / / B 3 L Y P / 6-31 G \star \cap L A N L 2 D Z$, the solvent used in calculations is toluene) of the proton transfer. The energies are relative to the intermediate $\mathbf{1 8}$.

activation $^{37}$. We next explored the polar monomer enchainment step by SAESI-MS. When 2a, VA and MMAO were mixed in situ (mimicking Procedure A), an intense signal at $\mathrm{m} / \mathrm{z} 1377$ was observed (Fig. 2d). This signal could be reasonably deduced as species (2ab). However, only the signal at $\mathrm{m} / \mathrm{z} 1291$ corresponding to $[\mathbf{2 a}-2 \mathrm{Br}+\mathrm{H}]^{+}$, instead of the chelating species $\mathbf{2 a b}([\mathbf{2 a} \mathbf{a}-$ $2 \mathrm{Br}+\mathrm{H}+\mathrm{VA}]^{+}, \mathrm{m} / \mathrm{z}$ 1377), was observed when VA was pretreated with MMAO for $24 \mathrm{~h}$ before contacting $2 \mathrm{a}$ (Procedure B, Supplementary Fig. 3). The formation of $2 \mathbf{a b}(\mathrm{I})$ and $\mathbf{2 a b}(\mathrm{II})$ due to 2,1- or 1,2-insertion of VA into the $\mathrm{Ni}-\mathrm{H}$ is consistent with the results of control experiment (Supplementary Methods 1.7, Supplementary Table 2). These results suggest the catalytic species is very likely still a nickel cluster and the aforementioned abnormal effects are associated with $\mathrm{Ni} \cdots \mathrm{Ni}$ synergetic effects.

To further understand the different results of SAESI-MS spectra, we monitored the reaction of MMAO + VA with a $2 / 1$ molar ratio by ${ }^{1} \mathrm{H}$ NMR (the same MMAO/VA molar ratio as in Table 2, entry 2). As shown in Fig. 2e, nearly $50 \%$ free VA is intact after mixing for $10 \mathrm{~min}$ (Procedure A). The peak at $12.55 \mathrm{ppm}$ was observed even after $30 \mathrm{~min}$. and gradually 
<smiles>CCCc1cccc(CCC)c1N=C(C)C(C)(O)C(C)=Nc1c(F)cccc1C(C)C</smiles>

28

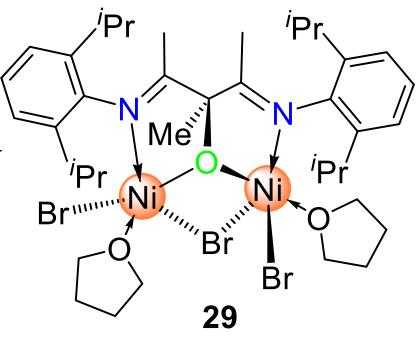

b

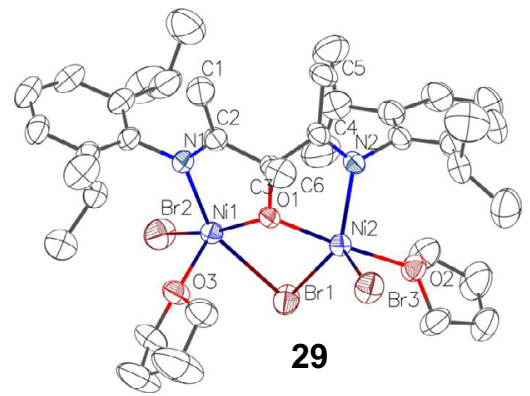

Fig. 4 Synthesis and structure of 29. a Synthesis of complex 29. b Single crystal structure of complex 29.

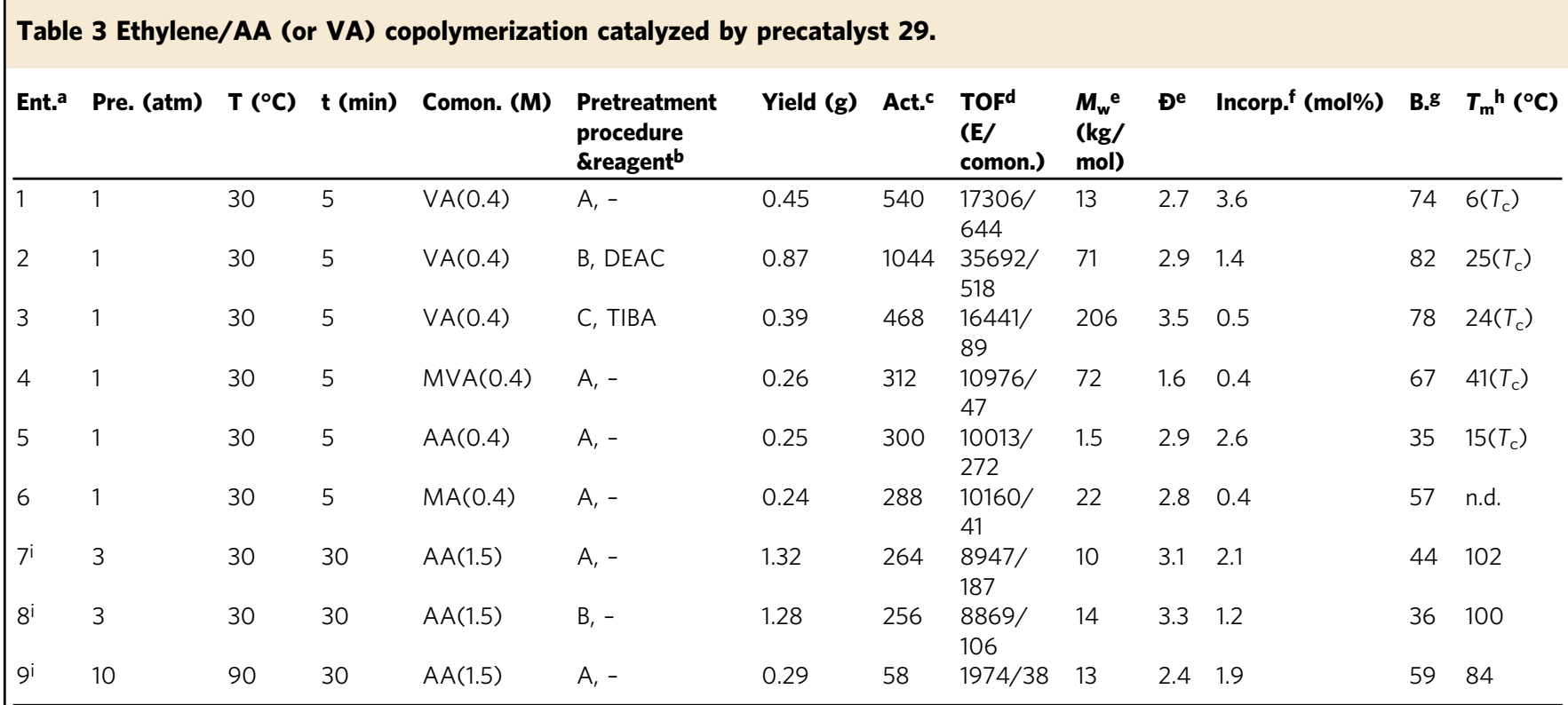

aConditions: toluene, $50 \mathrm{~mL}$; Cat. 29 ( 10 umol dissolved in $5 \mathrm{~mL}$ toluene), DEAC (3.0 M in toluene), $30 \mathrm{mmol}$. bProcedures A-C are similar to those in Table 2 except that MMAO is replaced with DEAC

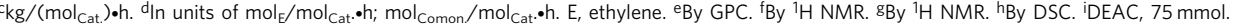

disappeared in $1 \mathrm{~h}$ (Procedure B). The existence of active proton under Procedure A-type condition and the lack thereof under Procedure B-type condition suggests the proton might play a significant role in the activation procedure-associated abnormal effects in 2 catalyzed ethylene + VA copolymerization.

To clarify the $\mathrm{Ni}$... Ni synergistic effects ${ }^{43}$ and the role of proton in the copolymerization of ethylene with protic polar comonomers, we carried out DFT calculations. From a practical point of view, the growing polymer chain was modeled by an $n$-propyl group, the insertion product of the first ethylene insertion ${ }^{44}$. Initially, the computed energy difference between 18 and 18-1 $(\Delta \Delta \mathrm{G}=-7.7 \mathrm{kcal} / \mathrm{mol})$ shows that simultaneous coordination of anionic vinyl acetate via its $\mathrm{O}$ atom to $\mathrm{Ni} 2$ and its $\mathrm{C}=\mathrm{C}$ bond to Nil center is more favorable (Fig. 3a). The interaction between polar group and metal center ${ }^{36,45-49}$ changes the polar monomer coordination from an intermolecular to an intramolecular process. Further insertion of such intramolecularly coordinated olefin occurs at the center of Nil with an energy barrier of $\Delta G^{\ddagger}=15.5$ $\mathrm{kcal} / \mathrm{mol}$ (19-TS), yielding a seven-membered ring chelate product 20. This step is dramatically exergonic by $\Delta \mathrm{G}=-20.2$ $\mathrm{kcal} / \mathrm{mol}$. These results suggest that the bimetallic cooperative VA coordination/insertion is both kinetically and thermodynamically feasible. The seven-membered ring chelate product $\mathbf{2 0}$ readily undergoes ethylene coordination/insertion giving intermediate $\mathbf{2 3}$ with an energy barrier of $\Delta G^{\ddagger}=22.2 \mathrm{kcal} / \mathrm{mol}$ and exergonic by $\Delta \mathrm{G}=-12.4 \mathrm{kcal} / \mathrm{mol}$. Alternatively, 20 could also undergo chain- walking. In this case, the $\beta-\mathrm{H}$ elimination is more kinetically favorable than ethylene insertion (energy barrier of 19.7 vs. $22.2 \mathrm{kcal} / \mathrm{mol}$ ) (Fig. 3a). Furthermore, the re-insertion of the resulting $\mathrm{Ni}-\mathrm{H}$ bond in $\mathbf{2 6}$ to give $\mathbf{2 7}$ is also exergonic. Though the re-insertion transition state was not located, this step should be kinetically accessible ${ }^{50}$. The results agree with the SAESI-MS studies which identified a strong signal that corresponds to $2 \mathbf{a b}$ in the in situ mixed 2a/MMAO/VA system and suggest the formation of copolymers with extended polar branches (Fig. 2d). This is consistent with the microstructural analysis of the copolymers by a combined NMR experiments $\left({ }^{1} \mathrm{H},{ }^{13} \mathrm{C}, \mathrm{HSQC}\right.$, and $\mathrm{HMBC}$ ), in which the $-\mathrm{COOH}$ groups are observed at the end of branches with varied branch lengths (Supplementary Note 1 and Supplementary Fig. 17).

In this proposed mechanistic scenario, the release of the -COONi from catalytic metal center is one of the key steps. DFT studies show that the proton could assist the release of the coordinating carboxyl group and thus allow further polar monomer enchainment in the copolymerization. As shown in Fig. 3b, the metallocycle in the intermediates such as $\mathbf{2 3}$, formed via $\mathrm{Ni} \cdots \mathrm{Ni}$ synergistic effects, eventually releases the coordinating carboxyl group via the proton transfer in the polymerization system, which circumvent chain termination and ensures multiple and efficient polar monomer enchainment. DFT calculations do show such a process is both thermodynamically and kinetically feasible $\left(\Delta \mathrm{G}=-9.3 \mathrm{kcal} / \mathrm{mol} ; \Delta \mathrm{G}^{\ddagger}=26.8 \mathrm{kcal} / \mathrm{mol}\right)$. 
Combining the aforementioned results of ${ }^{1} \mathrm{H}$ NMR studies, this explains well the observations that copolymerizations following Procedure A afford greater VA enchainment than those following Procedures B and C.

Binuclear nickel catalyst and the copolymerization of ethylene with VA or AA. The above studies show that tetranuclear cluster 2 could greatly enhance the enchainment of various protic monomers vs. aprotic analogs. We are glad to observe similar trends in catalysis with binuclear complex $\mathbf{2 9}$, which has a shorter $\mathrm{Ni} \cdots \mathrm{Ni}$ distance than those of $\mathbf{2 a}$ and $\mathbf{2 c}(3.259 \AA$ vs. $\sim 3.33 \AA$ ) (Fig. 4). Moreover, 29 gave both higher activities and higher incorporation of AA or VA compared with complexes 2, in particular for the industrially more relevant AA monomer (Table 3). For example, upon activation with $\mathrm{Et}_{2} \mathrm{AlCl}$ (DEAC), 29 gave an activity of $300 \mathrm{~kg} /(\mathrm{mol}$ Cat.).h with $2.6 \mathrm{~mol} \%$ AA incorporation-8.7× higher than that of $\mathbf{2 a}$ (Table 3 , entry 5 vs. Table 2, entry 20). Similar protic acid comonomer preference (VA and AA) vs. aprotic MVA and MA was also observed (entry 1 vs. 4; entry 5 vs. 6). Notably, 29 exhibits good thermal stability over 30 min even at $90^{\circ} \mathrm{C}$ under $10 \mathrm{~atm}$ ethylene (entry 9). Thus, binuclear complex 29 achieved the highest TOFs for the copolymerization of ethylene with VA and $\mathrm{AA}^{25-27}$.

In summary, tetranuclear nickel complexes 2 prove successful precatalysts for direct copolymerization of ethylene with protic comonomers with high activity and incorporation. In contrast to known systems, 2 show much higher efficiency in enchaining VA without compromising activity or $M_{\mathrm{w}}$ capability vs. its aprotic analog MVA. This distinctive protic polar monomer preference is also observed for a range of other protic polar monomers such as allylacetic acid, $\omega$-alkenoic acid, allyl alcohol, and homoallyl alcohol, etc. SAESI-MS captured the signal of $[2 \mathbf{a}-2 \mathrm{Br}+\mathrm{H}+\mathrm{VA}]^{+}$in mimicking the copolymerization procedure, suggesting the active species is likely still tetranuclear nickel species. ${ }^{1} \mathrm{H}$ NMR studies on the mixed VA + MMAO show proton exists within $30 \mathrm{~min}$, corroborating with all polymerizations results, suggesting the important role the proton might play in the copolymerization. Based on the experimental results and DFT calculations, a rationale involving enchainment of VA enabled by distinctive $\mathrm{Ni} \cdots \mathrm{Ni}$ synergistic effects is proposed. Inspired by the mechanistic insights, the designed binuclear precatalyst 29 with shorter $\mathrm{Ni} \cdots \mathrm{Ni}$ distance is synthesized, which is much more efficient for the copolymerization of ethylene with VA and AA than tetranuclear complexes 2 . Thus, we developed a potentially useful catalyst to enchain the industry-relevant monomers $\mathrm{AA}$ and VA into $\mathrm{PE}$ backbone, achieving the highest TOFs for the copolymerization of ethylene with VA and AA. This finding shows multinuclear catalysis as an effective strategy in direct coordination copolymerization of ethylene and protic comonomer and paves a way for the design of catalyst in the synthesis of functionalized PEs.

\footnotetext{
Methods

General Information. For synthetic procedures, NMR spectra of compounds, NMR, GPC, and ATR-IR spectra of polymers, see Supplementary Methods and Supplementary Figs. 14-36. For details on SAESI-MS studies of key species, see Supplementary Methods 1.6 and Supplementary Figs. 1-5. Model experiments to determine the insertion mode of polar monomers are given in Supplementary Methods 1.7 and Supplementary Figs. 6-8. NMR study of VA and butyric acid (BA) mixed with MMAO is shown in Supplementary Methods 1.8 and Supplementary Fig. 9. Computational studies can be found in Supplementary Note 4 and Supplementary Figs. 10-13. Polar copolymer microstructure analysis is given in Supplementary Note 1 . Branching analysis from ${ }^{1} \mathrm{H}$ NMR and ${ }^{13} \mathrm{C}$ NMR and polar monomer incorporation analysis from ${ }^{1} \mathrm{H}$ NMR are outlined in Supplementary Note 2 and 3.
}

\section{Data availability}

Experimental procedures and characterizations, including detailed experimental procedures, NMR spectra, complete polymerization experiment information, analysis of the polymer structure, and computational details are available in the Supplementary Information. The data that support the plots within this paper are available from the corresponding authors upon reasonable request. The X-ray crystallographic coordinates for structures reported in this study have been deposited at the Cambridge Crystallographic Data Centre (CCDC), under deposition numbers CCDC1575003 (2a), CCDC1575004 (2c), CCDC1575009 (7) and CCDC206294229 (29). These data can be obtained free of charge from The Cambridge Crystallographic Data Centre via www.ccdc.cam.ac.uk/data_request/cif.

Received: 3 August 2021; Accepted: 28 September 2021; Published online: 01 November 2021

\section{References}

1. Schöbel, A., Winkenstette, M., Anselment, T. M. J. \& Rieger, B. 3.24Copolymerization of alkenes and polar monomers by early and late transition metal catalysts. In Polymer Science: A Comprehensive Reference, Matyjaszewski, K. \& Möller, M. Eds. Elsevier: Amsterdam, pp 779-823 (2012)

2. Chung, T. C. In Functionalization of Polyolefins (ed T. C. Chung) 65-78 (Academic Press, 2002).

3. Chen, J., Gao, Y. \& Marks, T. J. Early transition metal catalysis for olefin-polar monomer copolymerization. Angew. Chem., Int. Ed. 59, 14726-14735 (2020).

4. Yang, X.-H. et al. [O-NSR]TiCl3-catalyzed copolymerization of ethylene with functionalized olefins. Angew. Chem. Int. Ed. 48, 8099-8102 (2009).

5. Terao, H., Ishii, S., Mitani, M., Tanaka, H. \& Fujita, T. Ethylene/polar monomer copolymerization behaviour of bis(phenoxy-imine)Ti complexes: formation of polar monomer copolymers. J. Am. Chem. Soc. 130, 17636-17637 (2008).

6. Liang, T., Goudari, S. B. \& Chen, C. A simple and versatile nickel platform for the generation of branched high molecular weight polyolefins. Nat. Commun. 11, 372-380 (2020).

7. Kocen, A. L., Brookhart, M. \& Daugulis, O. A highly active Ni(II)triadamantylphosphine catalyst for ultrahigh-molecular-weight polyethylene synthesis. Nat. Commun. 10, 438-444 (2019).

8. Chen, C. Designing catalysts for olefin polymerization and copolymerization beyond electronic and steric tuning. Nat. Rev. Chem. 2, 6-14 (2018).

9. Chen, Z. \& Brookhart, M. Exploring ethylene/polar vinyl monomer copolymerizations using $\mathrm{Ni}$ and $\mathrm{Pd}$ a-diimine catalysts. Acc. Chem. Res. 51, 1831-1839 (2018).

10. Mu, H., Pan, L., Song, D. \& Li, Y. Neutral nickel catalysts for olefin homo- and copolymerization: relationships between catalyst structures and catalytic properties. Chem. Rev. 115, 12091-12137 (2015).

11. Nakamura, A. et al. Ortho-phosphinobenzenesulfonate: a superb ligand for palladium-catalyzed coordination-insertion copolymerization of polar vinyl monomers. Acc. Chem. Res. 46, 1438-1449 (2013).

12. Younkin, T. R. et al. Neutral, single-component nickel (II) polyolefin catalysts that tolerate heteroatoms. Science 287, 460-462 (2000).

13. Guan, Z., Cotts, P. M., McCord, E. F. \& McLain, S. J. Chain walking: a new strategy to control polymer topology. Science 283, 2059-2062 (1999).

14. Zhang, Y., Wang, C., Mecking, S. \& Jian, Z. Ultrahigh branching of mainchain-functionalized polyethylenes by inverted insertion selectivity. Angew. Chem., Int. Ed. 59, 14296-14302 (2020).

15. Chen, Z., Leatherman, M. D., Daugulis, O. \& Brookhart, M. Nickel-catalyzed copolymerization of ethylene and vinyltrialkoxysilanes: catalytic production of cross-linkable polyethylene and elucidation of the chain-growth mechanism. J. Am. Chem. Soc. 139, 16013-16022 (2017).

16. Dai, S., Sui, X. \& Chen, C. Highly robust palladium(II) $\alpha$-diimine catalysts for slow-chain-walking polymerization of ethylene and copolymerization with methyl acrylate. Angew. Chem. Int. Ed. 54, 9948-9953 (2015).

17. Mecking, S. \& Schnitte, M. Neutral nickel(II) catalysts: from hyperbranched oligomers to nanocrystal-based materials. Acc. Chem. Res. 53, 2738-2752 (2020).

18. Jian, Z., Baier, M. C. \& Mecking, S. Suppression of chain transfer in catalytic acrylate polymerization via rapid and selective secondary insertion. J. Am. Chem. Soc. 137, 2836-2839 (2015).

19. Ito, S., Munakata, K., Nakamura, A. \& Nozaki, K. Copolymerization of vinyl acetate with ethylene by palladium/alkylphosphine-sulfonate catalysts. J. Am. Chem. Soc. 131, 14606-14607 (2009).

20. Drent, E., van Dijk, R., van Ginkel, R., van Oort, B. \& Pugh, R. I. Palladium catalysed copolymerisation of ethene with alkylacrylates: polar comonomer built into the linear polymer chain. Chem. Commun. 744-745 (2002).

21. Zhang, Y., Mu, H., Pan, L., Wang, X. \& Li, Y. Robust bulky $[\mathrm{P}, \mathrm{O}]$ neutral nickel catalysts for copolymerization of ethylene with polar vinyl monomers. ACS Catal. 8, 5963-5976 (2018).

22. Konishi, Y. et al. Nickel-catalyzed propylene/polar monomer copolymerization. ACS Macro Lett. 7, 213-217 (2018). 
23. Xin, B. S. et al. Nickel catalyzed copolymerization of ethylene and alkyl acrylates. J. Am. Chem. Soc. 139, 3611-3614 (2017).

24. Gladysz, J. A. et al. Organometallics Roundtable 2011. Organometallics 31, 1-18 (2012).

25. Chen, M. \& Chen, C. A versatile ligand platform for palladium- and nickelcatalyzed ethylene copolymerization with polar monomers. Angew. Chem. Int. Ed. 57, 3094-3098 (2018).

26. Zhang, D. \& Chen, C. Influence of polyethylene glycol unit on palladium- and nickel-catalyzed ethylene polymerization and copolymerization. Angew. Chem. Int. Ed. 56, 14672-14676 (2017).

27. Rünzi, T., Fröhlich, D. \& Mecking, S. Direct synthesis of ethylene-acrylic acid copolymers by insertion polymerization. J. Am. Chem. Soc. 132, 17690-17691 (2010).

28. Sun, J., Chen, M., Luo, G., Chen, C. \& Luo, Y. Diphosphazane-monoxide and phosphine-sulfonate palladium catalyzed ethylene copolymerization with polar Monomers: a computational study. Organometallics 38, 638-646 (2019).

29. Gaikwad, S. R. et al. Reactivity of difunctional polar monomers and ethylene copolymerization: a comprehensive account. Macromolecules 50, 5748-5758 (2017).

30. Zou, C. \& Chen, C. Polar-functionalized, crosslinkable, self-healing, and photoresponsive polyolefins. Angew. Chem. Int. Ed. 59, 395-402 (2020).

31. Sun, X.-L. \& Tang, Y. Sidearm approach to the synthesis of catalysts used in olefin polymerization. Acta Polym. Sin. 7, 1019-1037 (2017).

32. Chen, Z. et al. Copolymerization of ethylene with functionalized olefins by [ONX] titanium complexes. Macromolecules 46, 2870-2875 (2013).

33. Azoulay, J. D. et al. Nickel $\alpha$-keto- $\beta$-diimine initiators for olefin polymerization. Angew. Chem. Int. Ed. 48, 1089-1092 (2009).

34. Allinger, N. L., Zhou, X. \& Bergsma, J. Molecular mechanics parameters. J. Mol. Struct.: Theochem. 312, 69-83 (1994).

35. Rodriguez, B. A., Delferro, M. \& Marks, T. J. Neutral bimetallic nickel(II) phenoxyiminato catalysts for highly branched polyethylenes and ethylene -norbornene copolymerizations. Organometallics 27, 2166-2168 (2008).

36. Takeuchi, D., Chiba, Y., Takano, S. \& Osakada, K. Double-decker-type dinuclear nickel catalyst for olefin polymerization: efficient incorporation of functional co-monomers. Angew. Chem., Int. Ed. 52, 12536-12540 (2013).

37. Chen, E. Y.-X. \& Marks, T. J. Cocatalysts for metal-catalyzed olefin polymerization: activators, activation processes, and structure-activity relationships. Chem. Rev. 100, 1391-1434 (2000).

38. Carone, C. L. P. et al. Ethylene polymerization and copolymerization with 10undecen-1-ol using the catalyst system DADNi(NCS)2/MAO. J. Polym. Sci., Part A: Polym. Chem. 45, 5199-5208 (2007).

39. Correia, S. G. et al. Polymerization with TMA-protected polar vinyl comonomers. II. catalyzed by nickel complexes containing a-diimine-type ligands. J. Polym. Sci., Part A: Polym. Chem. 37, 2471-2480 (1999).

40. Tan, C. \& Chen, C. Emerging palladium and nickel catalysts for copolymerization of olefins with polar monomers. Angew. Chem. Int. Ed. 58, 7192-7200 (2019).

41. Zhou, Y.-Y. \& Uyeda, C. Catalytic reductive $[4+1]$-cycloadditions of vinylidenes and dienes. Science 363, 857-862 (2019).

42. Zhang, J.-T., Wang, H.-Y., Zhu, W., Cai, T.-T. \& Guo, Y.-L. Solvent-assisted electrospray ionization for direct analysis of various compounds (complex) from low/nonpolar solvents and eluents. Anal. Chem. 86, 8937-8942 (2014).

43. Delferro, M. \& Marks, T. J. Multinuclear olefin polymerization catalysts. Chem. Rev. 111, 2450-2485 (2011)

44. Chen, J., Motta, A., Zhang, J., Gao, Y. \& Marks, T. J. Mechanism of organoscandium-catalyzed ethylene copolymerization with amino-olefins: a quantum chemical analysis. ACS Catal. 9, 8810-8818 (2019).

45. Wang, C. et al. Heteroatom-assisted olefin polymerization by rare-earth metal catalysts. Sci. Adv. 3, e1701011 (2017).

46. Liu, D. et al. Stereoselective copolymerization of unprotected polar and nonpolar styrenes by an yttrium precursor: control of polar-group distribution and mechanism. Angew. Chem. Int. Ed. 56, 2714-2719 (2017).

47. Chen, J., Gao, Y., Wang, B., Lohr, T. L. \& Marks, T. J. Scandium-catalyzed selfAssisted polar co-monomer enchainment in ethylene polymerization. Angew. Chem. Int. Ed. 56, 15964-15968 (2017).
48. Takano, S., Takeuchi, D., Osakada, K., Akamatsu, N. \& Shishido, A. Dipalladium catalyst for olefin polymerization: introduction of acrylate units into the main chain of branched polyethylene. Angew. Chem. Int. Ed. 53, 9246-9250 (2014)

49. Radlauer, M. R., Buckley, A. K., Henling, L. M. \& Agapie, T. Bimetallic coordination insertion polymerization of unprotected polar monomers: copolymerization of amino olefins and ethylene by dinickel bisphenoxyiminato catalysts. J. Am. Chem. Soc. 135, 3784-3787 (2013).

50. Szabo, M. J. et al. Copolymerization of ethylene with polar monomers: chain propagation and side reactions. a DFT theoretical study using zwitterionic $\mathrm{Ni}(\mathrm{II})$ and Pd(II) catalysts. J. Am. Chem. Soc. 127, 14692-14703 (2005).

\section{Acknowledgements}

The authors are grateful for financial support by the National Natural Science Foundation of China (21690072, 21672237, U1862115, 22071015, 21901253), the Chinese Academy of Sciences (XDB 20000000, QYZDB-SSWSLH016), and the National Key Research and Development Program (2016YFA0202900) as well as the Science and Technology Commission of Shanghai Municipality (17JC1401200) and Youth Innovation Promotion Association CAS (No. 2020259).

\section{Author contributions}

Y.T. and X.-L.S. conceived the study; Y.T., X.-L.S., X.-Y.W., J.-F.L., and Q.S. planned the research; G.J., Z.C., X.-S.N, C.-J.X., X.-M.Z, and W.-J.T. synthesized and characterized the compounds; G.J., Z.C., and C.-J.X. conducted the olefin polymerization experiments; H.-Y.W., J.-B.Z., B.Z., and Y.-L.G. conducted the SAESI-MS Studies; Y.Z., J.S., and Y.L. designed and conducted the DFT calculations and analysis; Y.T., X.-L.S. X.-Y.W., and Y.G. prepared the manuscript; all the authors commented on the manuscript.

\section{Competing interests}

The authors declare no competing interest.

\section{Additional information}

Supplementary information The online version contains supplementary material available at https://doi.org/10.1038/s41467-021-26470-x.

Correspondence and requests for materials should be addressed to Xiu-Li Sun, Yin-Long Guo, Yi Luo or Yong Tang.

Peer review information Nature Communications thanks the anonymous reviewer(s) for their contribution to the peer review of this work.

Reprints and permission information is available at http://www.nature.com/reprints

Publisher's note Springer Nature remains neutral with regard to jurisdictional claims in published maps and institutional affiliations.

Open Access This article is licensed under a Creative Commons Attribution 4.0 International License, which permits use, sharing, (c) (i) adaptation, distribution and reproduction in any medium or format, as long as you give
appropriate credit to the original author(s) and the source, provide a link to the Creative appropriate credit to the original author(s) and the source, provide a link to the Creative
Commons license, and indicate if changes were made. The images or other third party material in this article are included in the article's Creative Commons license, unless indicated otherwise in a credit line to the material. If material is not included in the article's Creative Commons license and your intended use is not permitted by statutory regulation or exceeds the permitted use, you will need to obtain permission directly from the copyright holder. To view a copy of this license, visit http://creativecommons.org/ licenses/by/4.0/.

(C) The Author(s) 2021 